\title{
A survival comparison of gastric mucin- producing adenocarcinoma to conventional adenocarcinoma: a SEER database analysis
}

\author{
Qiang Wang ${ }^{1,2+}$, Junbin Zhong ${ }^{2 \dagger}$, Qing Huang ${ }^{2 \dagger}$, Zhuanpeng Chen ${ }^{2}$, Jianchang Wei ${ }^{1,2^{*}}$, Fang Wei ${ }^{2^{*}}$ and Jie Cao ${ }^{1,2^{*}}$
}

\begin{abstract}
Background: Compared to conventional adenocarcinoma (CA), mucin-producing adenocarcinoma (MPA) is an uncommon histological subtype and is usually separated from other histological types and has been evaluated separately. The objective was to compare the clinicopathological characteristics and survivals of MPA with CA.

Methods: We retrospectively analyzed 1515 MPA patients in SEER database. Log-rank tests and KM survival curves were applied to determine the differences in overall survival (OS) and cancer specific survival (CSS) time.

Results: No significant differences were noted in OS and CSS time. The MPA patients who were treated with surgery and chemotherapy exhibited longer OS and CSS time periods than those without treatment. MPA patients treated with radiotherapy exhibited similar OS and CSS time with those without radiotherapy. MPA was not a prognostic factor of survival.

Conclusions: MPA was a rare histological type of gastric cancer. Patients with MPA exhibited similar prognosis with those with CA. Surgery and chemotherapy were effective treatments for patients with MPA.
\end{abstract}

Keywords: Gastric mucin-producing adenocarcinoma, Survival, SEER database

\section{Background}

Gastric cancer (GC) is an important digestive cancer encountered worldwide that ranks the fifth most frequently diagnosed cancer and the third leading cause of cancer death [1].

GC is histologically divided into two categories as follows: differentiated and undifferentiated cancer [2]. Differentiated cancers include well differentiated, moderately differentiated and papillary adenocarcinomas, whereas, undifferentiated tumors include signet ring cell carcinoma,

\footnotetext{
*Correspondence: Eywei12600@scut.edu.cn; 15521287698@126.com; eycaojie@scut.edu.cn

${ }^{+}$Qiang Wang, Junbin Zhong and Qing Huang contributed equally to this work.

${ }^{1}$ The First Affiliated Hospital, Jinan University, Guangzhou, Guangdong, China ${ }^{2}$ Department of General Surgery, Guangzhou Digestive Disease Center, Guangzhou First People's Hospital, School of Medicine, South China University of Technology, Guangzhou, Guangdong, China
}

poorly differentiated and mucinous adenocarcinomas [3]. Compared to differentiated cancer, undifferentiated cancer demonstrates aggressive growth, proliferation, invasiveness, metastasis and poor prognosis [3].

Mucin-producing adenocarcinoma (MPA), such as mucinous adenocarcinoma and signet ring cell carcinoma, have the characteristics of producing mucin by the presence of intracellular or extracellular mucin pool [4]. Mucinous adenocarcinoma is characterized with more than $50 \%$ of extracellular mucin, and signet-ring cell carcinoma is characterized with more than $50 \%$ cells that contain intracellular mucin. The latter cause a certain movement of the nucleus to one side in order to create the characteristic morphology [5]. Compared to conventional adenocarcinoma (CA), MPA is an uncommon histological subtype and is considerably different in morphology, cell characteristics and protein expression

C The Author(s). 2021 Open Access This article is licensed under a Creative Commons Attribution 4.0 International License, which permits use, sharing, adaptation, distribution and reproduction in any medium or format, as long as you give appropriate credit to the original author(s) and the source, provide a link to the Creative Commons licence, and indicate if changes were made. The images or other third party material in this article are included in the article's Creative Commons licence, unless indicated otherwise in a credit line to the material. If material is not included in the article's Creative Commons licence and your intended use is not permitted by statutory regulation or exceeds the permitted use, you will need to obtain permission directly from the copyright holder. To view a copy of this licence, visit http://creativecommons.org/licenses/by/4.0/ The Creative Commons Public Domain Dedication waiver (http://creativecommons.org/publicdomain/zero/1.0/) applies to the data made available in this article, unless otherwise stated in a credit line to the data. 
[6]. Therefore, MPA is usually separated from other histological types and has been evaluated separately [3].

The clinicopathological characteristics and the prognosis of gastric MPA patients have been investigated in several studies. However, the results are inconsistent and the prognostic significance of MPA is still unclear. MPA was initially reported to be correlated with unfavorable prognosis than other histological types [7-10]. In contrast to these findings, other studies demonstrated no significant differences in disease prognosis [11-15]. MPA has not been reported as a negative prognostic factor [16-18]. It is important to state that signet ring cell carcinoma is associated with a favorable prognosis compared with other types of gastric cancer [19-22].

Therefore, further investigations are essential in identifying the clinicopathological characteristics and prognostic value of MPA. In the present study, we retrospectively analyzed 1515 MPA gastric cancer patients in the Surveillance, Epidemiology and End Results (SEER) database in order to compare the clinicopathological characteristics and survival outcomes of MPA with CA.

\section{Materials \& methods}

\section{Patient selection}

Clinicopathological data derived from gastric cancer patients were collected from the SEER database (18 Regs Custom Data with additional treatment fields,, 19752016 varying) using SEER*Stat 8.3.8 (http://seer.cancer. gov). The patient information in the SEER database is anonymous and ethical consent was not required for using these data $[23,24]$.
We collected the information of the patients diagnosed with GC from the SEER database during 2004-2015, because we required the TNM stage information from American Joint Committee on Cancer (AJCC) 6th (2004) edition for analysis.

The histological type of GC was defined as follows: code 8140 corresponded to adenocarcinoma and codes 8480 (Mucinous adenocarcinoma), 8481(Mucin-producing adenocarcinoma) and 8490 (Signet ring cell carcinoma) to mucin-producing adenocarcinoma.

The clinicopathological information of patients including age, sex race, tumor differentiation, tumor invasion, node, metastasis (TNM) stage, surgery, chemotherapy, radiation and survival time was collected from the SEER database.

The patients who $<18$ years old, without positive histology, with distant metastasis, with multiple primary tumors, with unknown follow up time and information were excluded.

Overall survival (OS) is the survival time from patient's diagnosis of the disease to death, and cancer specific survival (CSS) is the survival time from patient's diagnosis of the disease to death specific attributable to the cancer.

\section{Statistical analysis}

The Chi-square test was applied to determine the differences in the clinicopathological characteristics between the MPA and the CA groups. The log-rank test and Kaplan-Meier survival curve were applied to determine the differences in OS and CSS time periods between the MPA and the CA groups. Cox regression models were applied to assess the association between

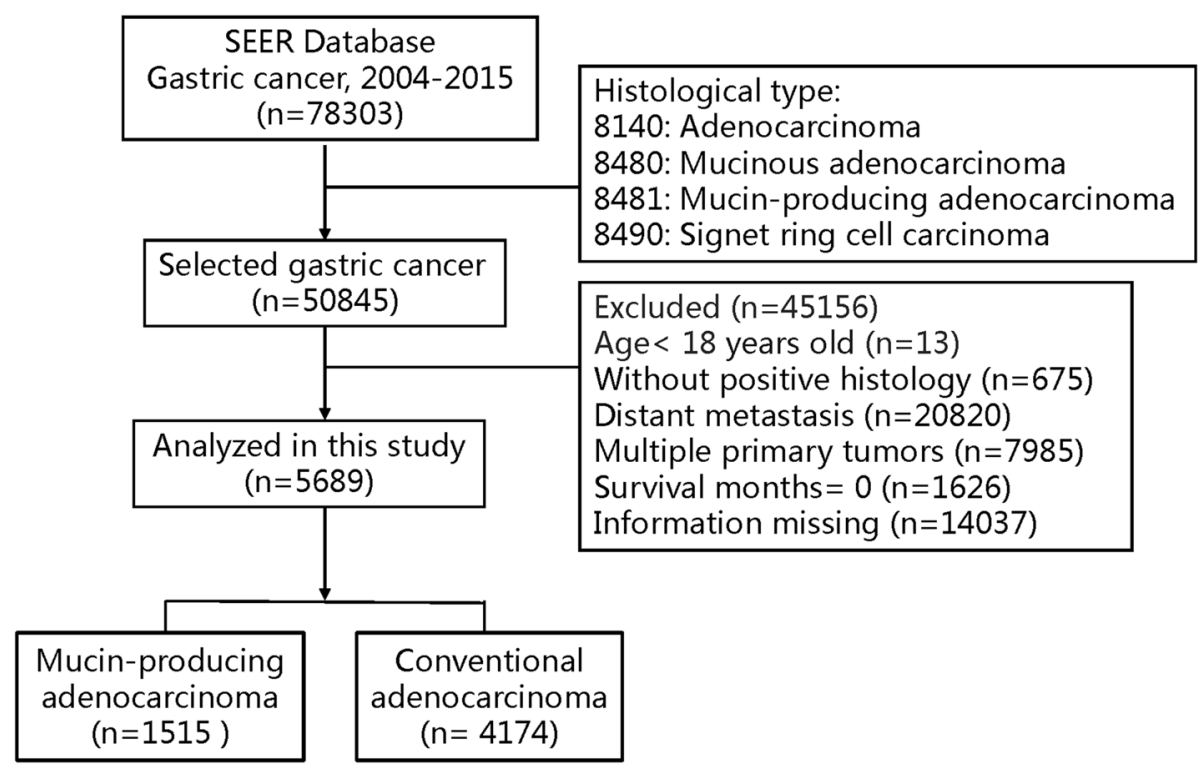

Fig. 1 Flowchart of the patients' selection process 
histological types and OS following adjustment for potential confounders, such as age, race, married status, tumor differentiation, clinical stage, surgery, chemotherapy and radiotherapy. The analysis was performed by Empower (R) (X\&Y solutions, inc. Boston MA, www.empowerstats.com) and R (http://www.Rproject.org).

\section{Results}

\section{Patient characteristics}

The selection flow of the patients is shown in Fig. 1. A total of 5689 eligible patients were selected from the SEER database during the period 2004-2015, of which 1515 patients $(26.6 \%)$ presented with MPA and 4174 patients $(73.4 \%)$ with CA.

The clinicopathological characteristics of the two groups are summarized in Table 1 . Overall, age, gender, race, tumor differentiation, clinical stage, $\mathrm{T}$ stage, $\mathrm{N}$ stage, surgery and chemotherapy were significantly different between MPA and CA, i.e., patients in the MPA group exhibited younger, more females, more black people, more poor/undifferentiated tumors, later clinical stage, more T3, T4, N2 stages, more surgery and chemotherapy than those of the CA group. No difference was noted in radiotherapy.

\section{Survival analysis by histological type}

To investigate whether MPA patients exhibit different survival time with CA patient, we compared the OS and CSS time between the two groups. The OS time in the MPA group was $58.67 \pm 1.67$ months, whereas that in the CA group was $55.68 \pm 1.00$ months; however, no significant difference was observed between the two groups (log-rank $=2.07, P=0.15$ ) (Fig. 2). The CSS time in the MPA group was $64.69 \pm 1.79$ months, whereas that in the CA group was $66 \pm 1.13$ months; however, no significant difference was observed between the two groups (log-rank $=0.185, P=0.67$ ) (Fig. 2).

To further determine whether MPA patients show similar survival time with CA patient in different subgroup, we compared the survival curves. As shown in Figs. 3 and 4, no significant differences were detected in OS times between the two groups with respect to different ages, genders, races and $\mathrm{N}$ stages. Interestingly, for patients with poor/ undifferentiated tumor, clinical stage I, T1 and T2, MPA patients had longer OS time than CA patients $(p<$ 0.05). As shown in Figs. 5 and 6, no significant differences were detected in CSS times between the two groups with respect to different ages, genders, races tumor differentiation, clinical stages, $\mathrm{T}$ stages and $\mathrm{N}$ stages (All $p>0.05$ ).

To further determine whether MPA patients show similar survival time with CA patient in different therapeutic
Table 1 Patients demographics and clinicopathological characteristics

\begin{tabular}{|c|c|c|c|c|}
\hline Variables & $\mathbf{n}$ & $\begin{array}{l}\text { MPA } \\
\text { n (\%) }\end{array}$ & $\begin{array}{l}\text { CA } \\
\text { n (\%) }\end{array}$ & $\mathbf{P}$ \\
\hline \multicolumn{5}{|c|}{ Age } \\
\hline$<60$ & 1996 & $692(45.7)$ & $1304(31.2)$ & 0.00 \\
\hline$\geq 60$ & 3693 & $823(54.3)$ & $2870(68.8)$ & \\
\hline \multicolumn{5}{|l|}{ Gender } \\
\hline Female & 1614 & $603(39.8)$ & $1011(24.2)$ & 0.00 \\
\hline Male & 4075 & $912(60.2)$ & $3163(75.8)$ & \\
\hline \multicolumn{5}{|l|}{ Race } \\
\hline White & 4332 & $1056(69.7)$ & $3276(78.5)$ & 0.00 \\
\hline Black & 593 & $192(12.7)$ & 401 (9.6) & \\
\hline Others & 764 & $267(17.6)$ & $497(11.9)$ & \\
\hline \multicolumn{5}{|l|}{ Differentiation } \\
\hline Well/ Moderate & 1885 & $121(8)$ & $1764(42.3)$ & 0.00 \\
\hline Poor/undifferentiated & 3804 & $1394(92)$ & $2410(57.7)$ & \\
\hline \multicolumn{5}{|l|}{ Clinical stage } \\
\hline I & 1764 & $401(26.5)$ & $1363(32.7)$ & 0.00 \\
\hline$\|$ & 2032 & $495(32.7)$ & $1537(36.8)$ & \\
\hline III & 1893 & $619(40.8)$ & $1274(30.5)$ & \\
\hline \multicolumn{5}{|l|}{ T stage } \\
\hline $\mathrm{T} 1$ & 877 & $193(12.7)$ & $684(16.4)$ & 0.00 \\
\hline $\mathrm{T} 2$ & 3089 & $799(52.8)$ & $2290(54.9)$ & \\
\hline T3 & 1564 & $473(31.2)$ & $1091(26.1)$ & \\
\hline T4 & 159 & $50(3.3)$ & 109 (2.6) & \\
\hline \multicolumn{5}{|l|}{$\mathrm{N}$ stage } \\
\hline NO & 1924 & $462(30.5)$ & $1462(35)$ & 0.00 \\
\hline N1 & 2861 & $707(46.7)$ & 2154 (51.6) & \\
\hline N2 & 904 & $346(22.8)$ & $558(13.4)$ & \\
\hline \multicolumn{5}{|l|}{ Surgery } \\
\hline Yes & 4123 & $1241(81.9)$ & $2882(69.1)$ & 0.00 \\
\hline No & 1566 & $274(18.1)$ & $1292(30.9)$ & \\
\hline \multicolumn{5}{|l|}{ Chemotherapy } \\
\hline Yes & 5101 & 1392 (91.9) & 3709 (88.9) & 0.001 \\
\hline No/ unkown & 588 & $123(8.1)$ & $465(11.1)$ & \\
\hline \multicolumn{5}{|l|}{ Radiotherapy } \\
\hline Yes & 5533 & $1472(97.2)$ & 4061 (92.3) & 0.78 \\
\hline No & 156 & $43(2.8)$ & $113(7.7)$ & \\
\hline
\end{tabular}

subgroups, we compared the survival curves. As shown in Fig. 7, MPA patients had shorter CSS time than CA patients after surgery, but there was no difference in OS time between the two groups. MPA patients without surgery had shorter OS and CSS time than that in CA patients. MPA patients had similar OS and CSS time with CA patients with or without radiotherapy/ chemotherapy. 


\section{Overall survival (OS)}

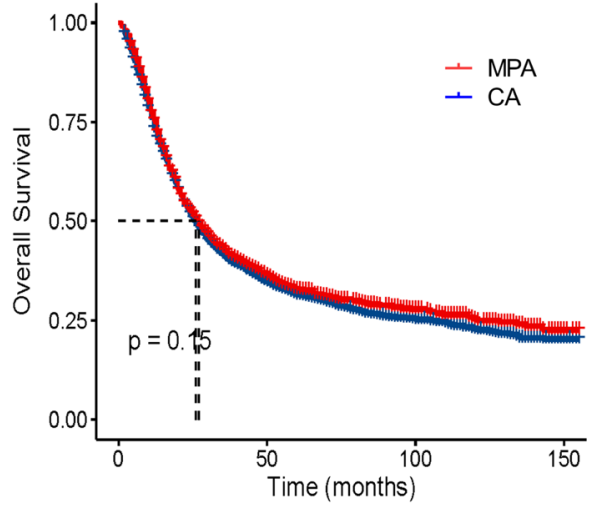

Cancer specific survival (CSS)

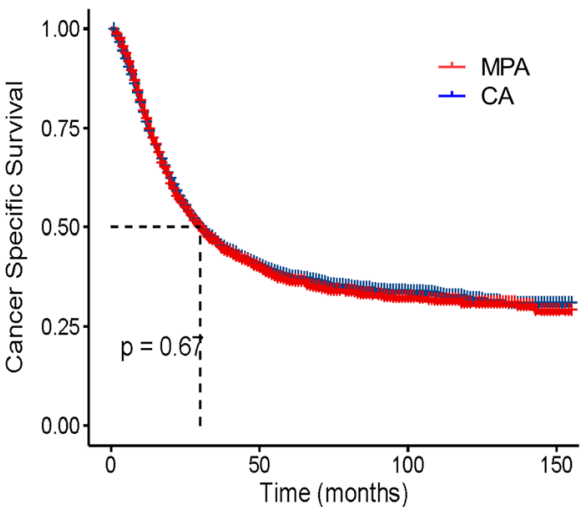

Fig. 2 Overall survival (OS) and cancer specific survival (CSS) analysis by different histological types of gastric cancer patients

\section{Survival analysis following treatments}

To investigate whether MPA patients obtained a survival benefit from different clinical therapies, we compared the OS and CSS time periods. As shown in Fig. 8, MPA patients who were treated with surgery exhibited longer OS and CSS time than those without surgery (both $P<0.05$ ). MPA patients treated with chemotherapy exhibited longer OS and CSS time than those without chemotherapy (both $\mathrm{P}<0.05$ ). MPA patients treated with radiotherapy exhibited similar OS

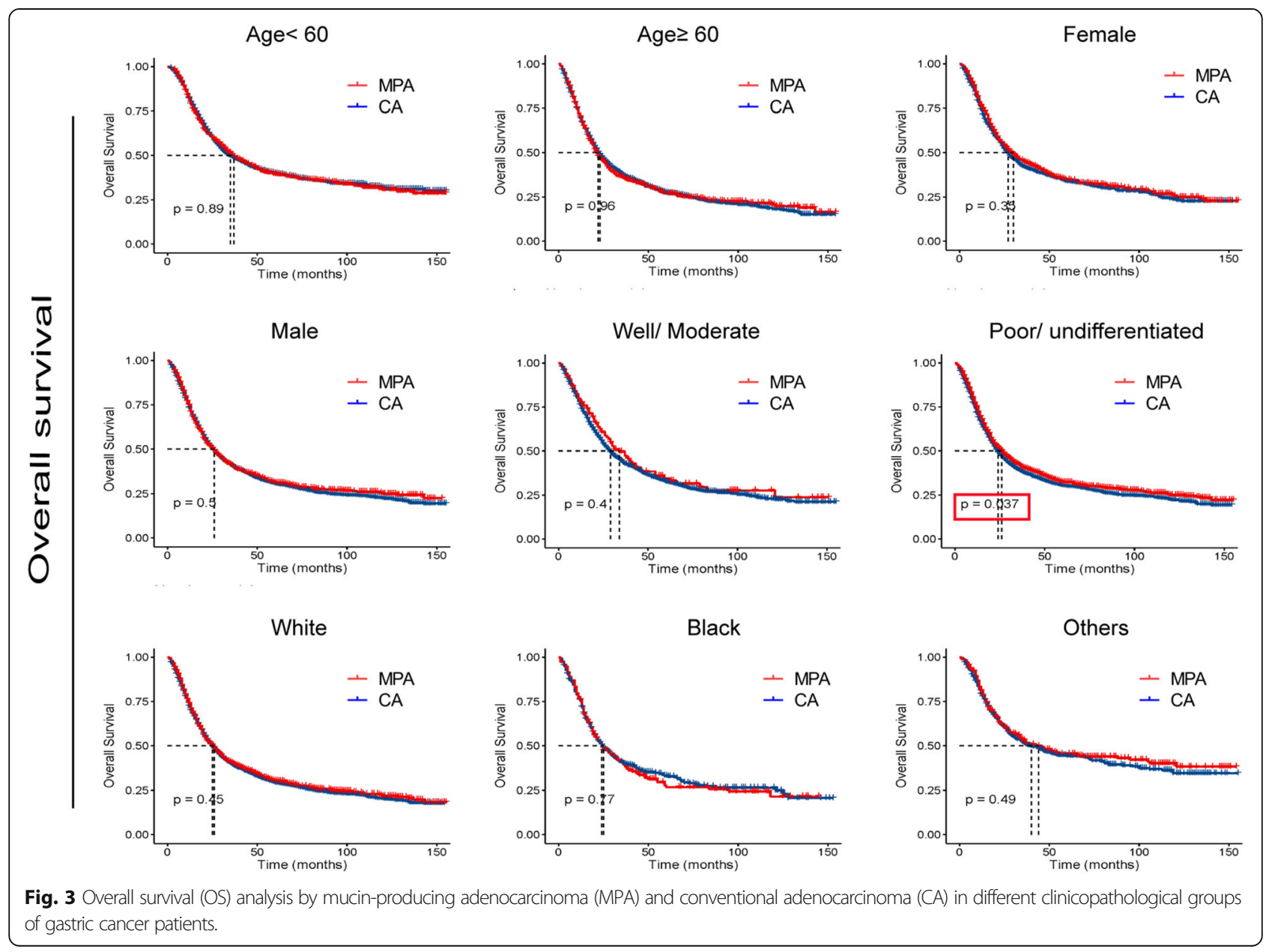




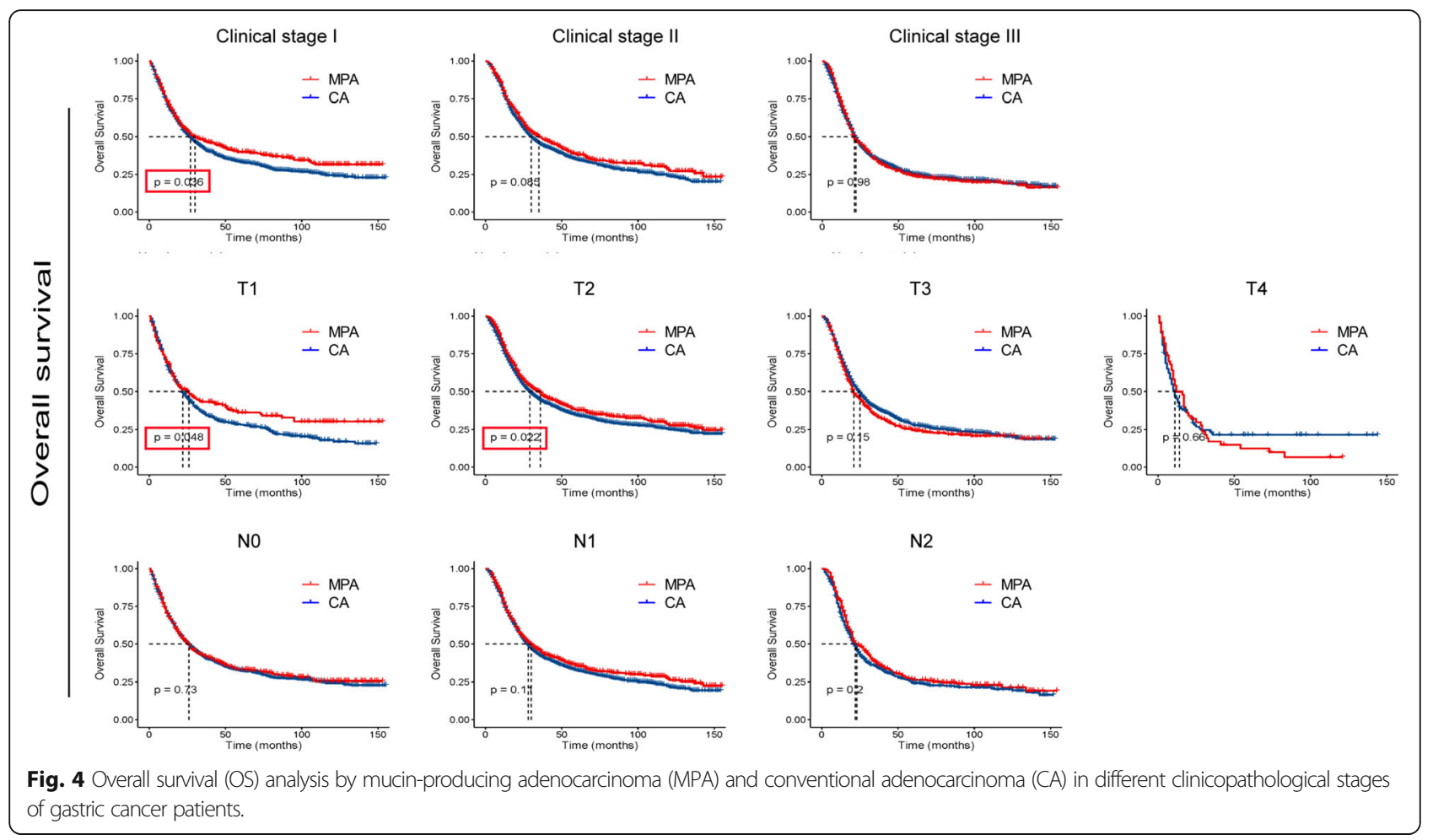

and CSS time with those without radiotherapy (both $P>0.05)$. Patients with CA obtained longer OS and CSS time when treated with surgery, chemotherapy and radiotherapy (All $p<0.05$ ).

\section{Adjusted survival analysis}

Cox regression was applied to analyze the association between histological type and overall survival following adjustment for baseline differences. As shown in Table 2, patients with MPA did not exhibit a significantly different hazard of death following adjustment for these variables $(P=0.15)$. For both groups, the significant independent prognostic factors were age, race, tumor differentiation, clinical stage, surgery and chemotherapy (All $P<0.05$ ). MPA histology was not a prognostic factors.

\section{Discussion}

MPA involves tumors, such as mucinous adenocarcinoma and signet ring cell carcinoma and produces mucin, which is observed by histological analysis [4]. Both of these two histological types are defined as undifferentiated $[3,25]$. Generally, the degree of cancer cell differentiation is associated with cancer aggressiveness. Undifferentiated cancer correlates with aggressive growth, invasion, metastasis and poor prognosis [3, 26].

However, the prognosis of gastric cancer patients with MPA is still controversial and unclear. Several studies have reported that MPA correlates with poor prognosis compared with other histological types [7-10], while other reports have not yielded significant differences in disease prognosis [11-15]. Moreover, it has also been shown that signet ring cell carcinoma is associated with a favorable prognosis than other types of gastric cancer [19-22].

Therefore, the present study retrospectively analyzed 1515 MPA gastric cancer patients from the SEER database in order to assess the prognostic value of MPA. In the present study, the proportion of MPA in gastric cancer was approximately $18.1 \% \quad(14,243 /$ 78303), which was considerably higher than that noted in previous studies $(2.6-6.6 \%)[3,12,14]$. The proportion of $\mathrm{CA}$ in gastric cancer was approximately $46.7 \%(36,602 / 78303)$. This evidence suggested that MPA was a rather rare histological type of gastric cancer. The data indicated that patients in the MPA group were younger, more females, more black people, more poor/undifferentiated tumors, later clinical stage, more T3, T4, N2 stages, more surgery and chemotherapy than that of the CA group, which suggested that MPA was an aggressive histological type. No significant differences were noted in the OS and CSS time periods between the MPA and the CA groups, suggesting that gastric cancer patients with MPA had similar prognosis with those with CA. However, for patients with poor/ undifferentiated tumor, clinical stage I, T1 and T2, MPA patients had 


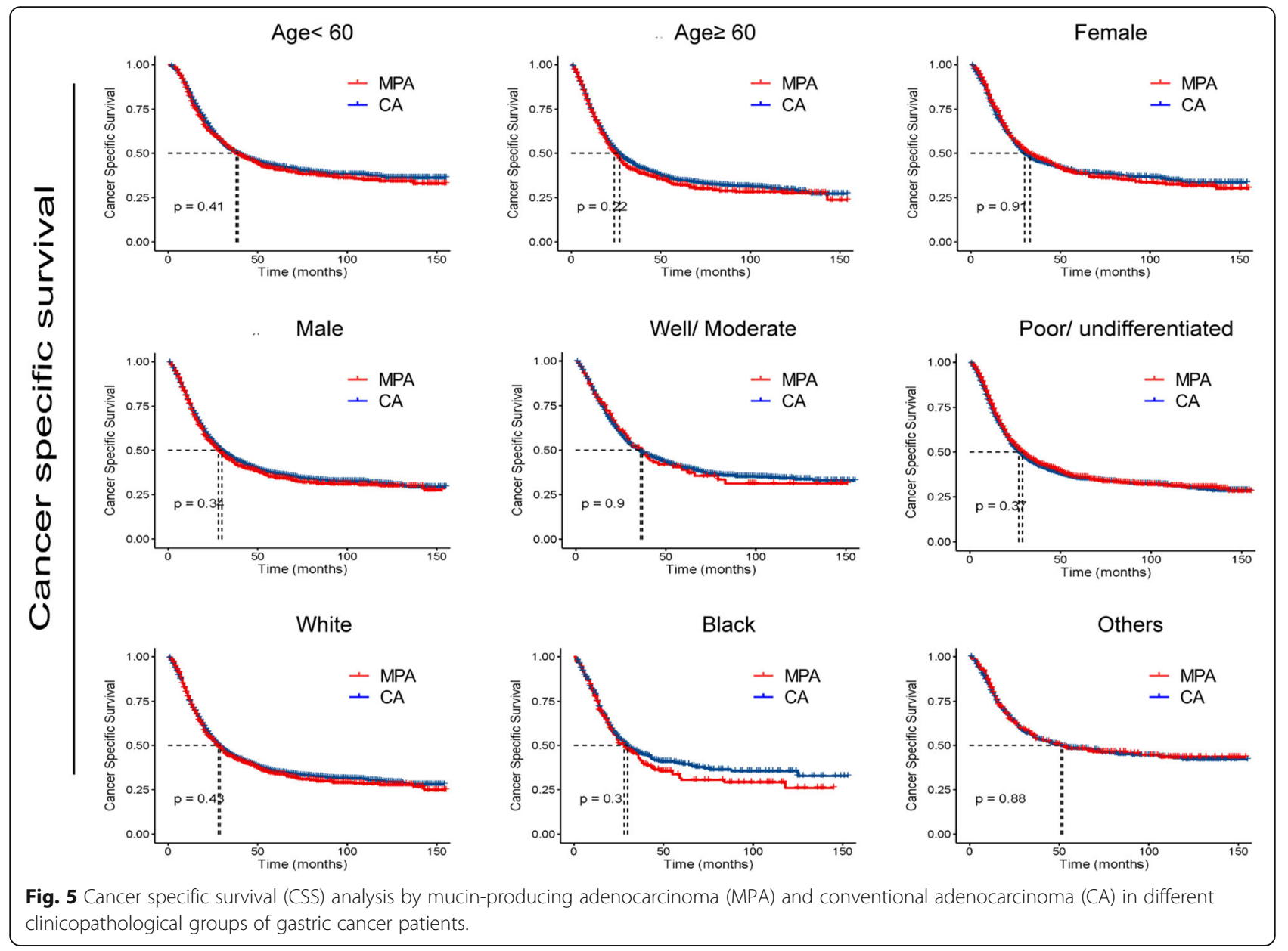

longer OS time than CA patients. MPA patients had shorter CSS time than CA patients after surgery, but there was no difference in OS time between the two groups. MPA patients without surgery had shorter OS and CSS time than that in CA patients. These results suggested that MPA patients had similar survival time with CA patients on the whole, but MPA was an aggressive histological type in some way. MPA was not a prognostic factor of survival. The results were basically in accordance with those from Zheng et al., who compared the CSS of esophageal cancer patients with MPA or CA and found similar survival time periods between the two groups [27].

With regard to the treatment of MPA, the patients who were treated with surgery or chemotherapy had longer OS and CSS time periods than those without treatment, suggesting that surgery and chemotherapy were effective treatments for early and localized gastric cancer patients with MPA. However, MPA patients treated with radiotherapy exhibited similar OS and CSS time with those without radiotherapy in this study, which indicated that radiotherapy may not be an effective treatment for gastric cancer patients with
MPA. However, pertinent information regarding radiotherapy was not available in the SEER database, which could have affected the results. Therefore, further investigations are required to identify the practical and clinical significance of radiotherapy for patients with MPA. Moreover, the therapeutic roles of chemotherapy and radiotherapy for patients with metastatic MPA were not conducted in this study and require further studies.

The present study has its limitations. Firstly, it was a retrospective study and the baseline characteristics of both groups were different, which unavoidably contained selection bias. Secondly, due to the rarity of MPA cases and the exclusion of MPA patients with missing data, the number of patients with MPA used in the present study was low, compared with CA, which may affect the results in a way. Thirdly, the SEER database does not collect several important information, such as the type and extent of surgery, details on chemotherapy and radiotherapy and disease recurrence, which could have affected the results. Therefore, larger studies are required to further determine the clinical and pathological roles of MPA. 
Wang et al. BMC Cancer

(2021) 21:1138

Page 7 of 9
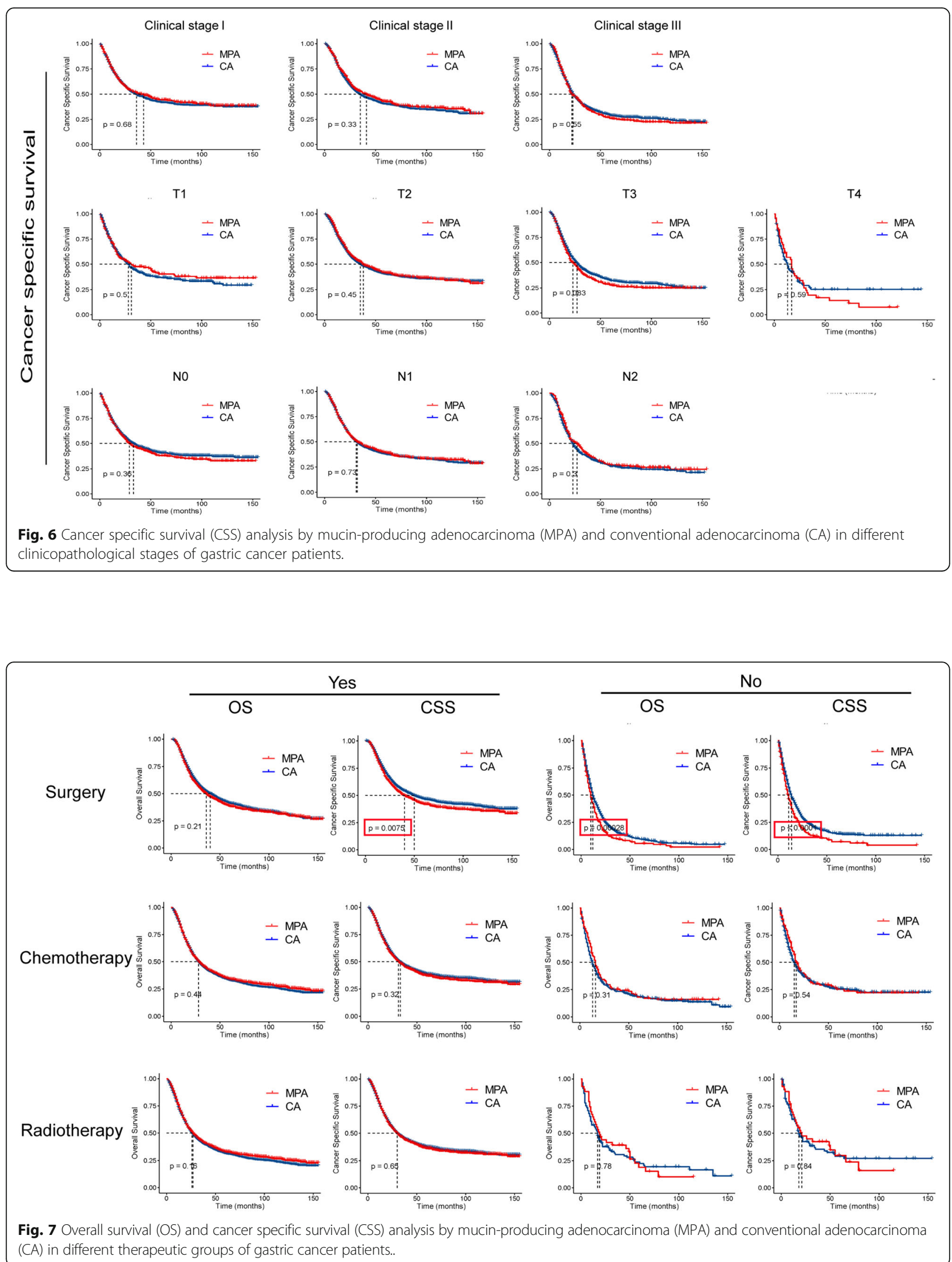


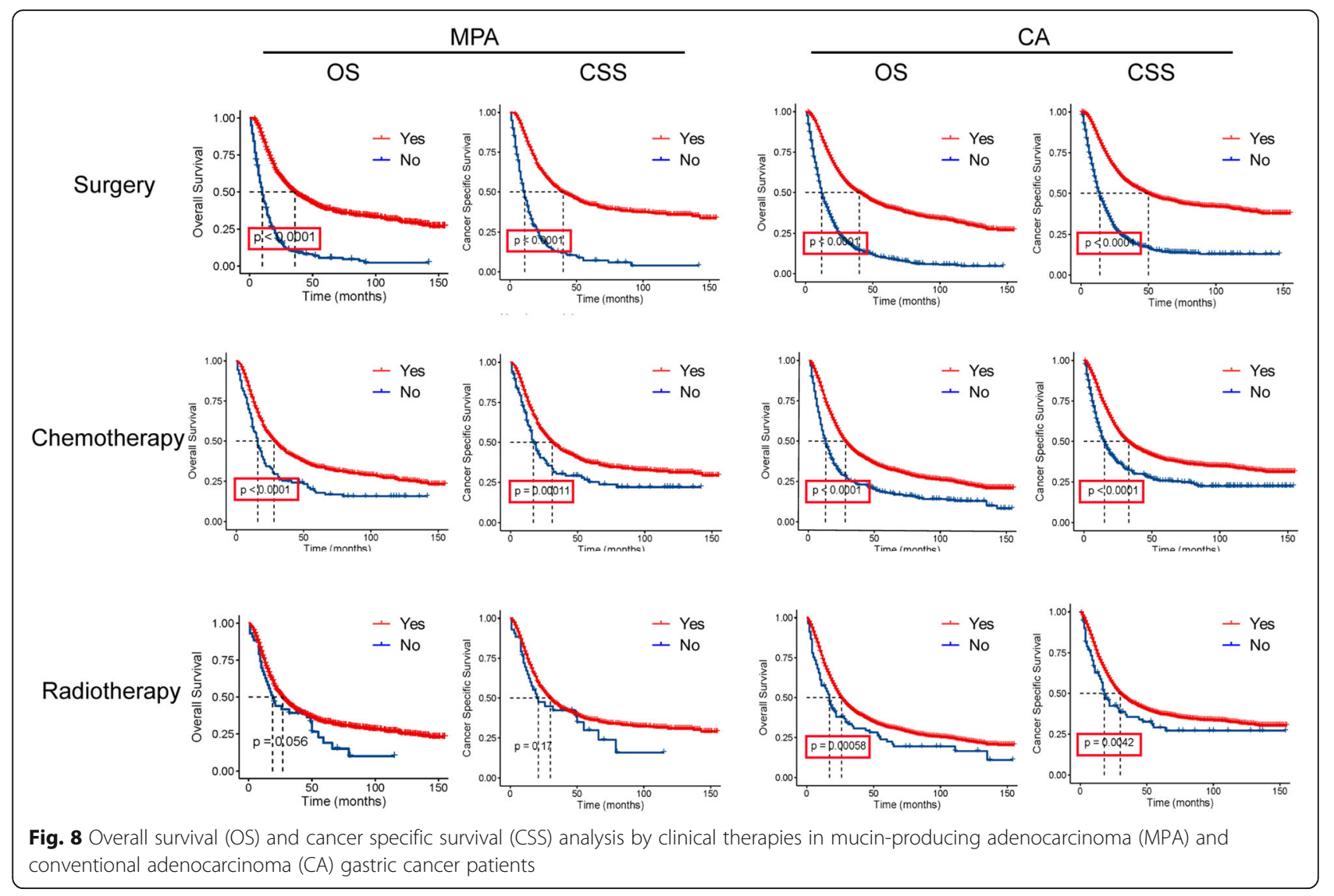

Table 2 Univariate and multivariate analysis of overall survival for gastric cancer patients

\begin{tabular}{|c|c|c|c|c|c|c|c|c|}
\hline & \multicolumn{4}{|c|}{ Univariate analysis } & \multicolumn{4}{|c|}{ Multivariate analysis } \\
\hline & \multirow[t]{2}{*}{ HR } & \multicolumn{2}{|l|}{$95 \% \mathrm{Cl}$} & \multirow[t]{2}{*}{$\mathrm{p}$} & \multirow[t]{2}{*}{ HR } & \multicolumn{2}{|l|}{$95 \% \mathrm{Cl}$} & \multirow[t]{2}{*}{ p } \\
\hline & & Lower & Upper & & & Lower & Upper & \\
\hline MPA vs.CA & 0.94 & 0.88 & 1.02 & 0.15 & - & - & - & - \\
\hline Age & 1.48 & 1.38 & 1.59 & 0.00 & 1.22 & 1.14 & 1.31 & 0.00 \\
\hline Race & 0.84 & 0.8 & 0.88 & 0.00 & 0.9 & 0.86 & 0.94 & 0.00 \\
\hline Gender & 1.08 & 1 & 1.16 & 0.03 & 1.04 & 0.97 & 1.12 & 0.24 \\
\hline Differentiation & 1.07 & 1 & 1.15 & 0.03 & 1.22 & 1.14 & 1.31 & 0.00 \\
\hline Clinical stage & 1.1 & 1.06 & 1.15 & 0.00 & 1.31 & 1.23 & 1.39 & 0.00 \\
\hline T stage & 1.08 & 1.03 & 1.13 & 0.00 & 0.98 & 0.92 & 1.04 & 0.59 \\
\hline $\mathrm{N}$ stage & 1.03 & 0.98 & 1.08 & 0.22 & - & - & - & - \\
\hline Surgery & 0.32 & 0.3 & 0.35 & 0.00 & 0.31 & 0.29 & 0.34 & 0.00 \\
\hline Chemotherapy & 0.55 & 0.5 & 0.61 & 0.00 & 0.69 & 0.62 & 0.76 & 0.00 \\
\hline Radiation & 0.69 & 0.58 & 0.83 & 0.00 & 0.88 & 0.72 & 1.08 & 0.23 \\
\hline
\end{tabular}




\section{Conclusions}

MPA is a rather rare histological type of gastric cancer. Patients with MPA had similar prognosis with those with CA. MPA was not an prognostic factor of survival. Surgery and chemotherapy were effective treatments for gastric cancer patients with MPA.

\section{Acknowledgements}

The authors thank SEER database for the public availability of the data.

\section{Authors' contributions}

Jianchang Wei, Fang Wei, and Jie Cao designed the study; Qiang Wang, Junbin Zhong and Qing Huang wrote the manuscript; Zhuanpeng Chen collected and analyzed the data. All authors read and approved the final manuscript.

\section{Funding}

None.

\section{Availability of data and materials}

The data used and analyzed during the study are available in SEER database (http://seer.cancer.gov).

\section{Declarations}

Ethics approval and consent to participate

Not applicable.

\section{Consent for publication}

Not applicable.

\section{Competing interests}

The authors declare that there is no competing interest.

Received: 7 May 2021 Accepted: 29 September 2021

Published online: 23 October 2021

\section{References}

1. Bray F, Ferlay J, Soerjomataram I, Siegel RL, Torre LA, Jemal A. Global cancer statistics 2018: GLOBOCAN estimates of incidence and mortality worldwide for 36 cancers in 185 countries. CA Cancer J Clin. 2018;68(6):394-424. https://doi.org/10.3322/caac.21492.

2. Sugano H, Nakamura K, Kato Y. Pathological studies of human gastric cancer. Acta Pathol Jpn. 1982:32:329-47.

3. Park JM, Jang YJ, Kim JH, Park SS, Park SH, Kim SJ, et al. Gastric cancer histology: clinicopathologic characteristics and prognostic value. J Surg Oncol. 2008;98(7):520-5. https://doi.org/10.1002/jso.21150.

4. Japanese Gastric Cancer Association. Japanese gastric cancer treatment guidelines 2014 (ver. 4). Gastric Cancer. 2017;20(1):1-19. https://doi.org/10.1 007/s10120-016-0622-4.

5. Hamilton SR, Aaltonen LA. World health organization classifcation of tumours. Pathologyand genetics. Tumours of the digestive system. IARC: Lyon; 2000.

6. Yang XF, Yang L, Mao XY, Wu DY, Zhang SM, Xin Y. Pathobiological behavior and molecular mechanism of signet ring cell carcinoma and mucinous adenocarcinoma of the stomach: acomparative study. World J Gastroenterol. 2004;10(5):750-4. https://doi.org/10.3748/wjg.v10.i5.750.

7. Wu CY, Yeh HZ, Shih RT, Chen GH. A clinicopathologic study of mucinous gastric carcinoma including multivariate analysis. Cancer. 1998;83(7):1312-8. https://doi.org/10.1002/(SICI)1097-0142(19981001)83:7<1312::AID-CNCR7>3.0. $\mathrm{CO} ; 2-\mathrm{K}$.

8. Pozos-Ochoa LI, Lino-Silva LS, León-Takahashi AM, Salcedo-Hernández RA. Prognosis of sig-net ring cell carcinoma of the colon and rectum and their distinction of mucinous adenocarcinoma with signet ring cells. A Comparativestudy. Pathol Oncol Res. 2018;24:609-16.

9. Hyngstrom JR, Hu CY, Xing Y, You YN, Feig BW, Skibber JM, et al. Clinicopathology and outcomes formucinous and signet ring colorectal adenocarcinoma: analysis from the national cancerdata base. Ann Surg Oncol. 2012;19:2814-21.
10. Piessen $G$, Messager $M$, Leteurtre $E$, Jean-Pierre $T$, Mariette $C$. Signet ring cell histology is an independent predictor of poor prognosis in gastric adenocarcinoma regardless of tumoral clinicalpresentation. Ann Surg. 2009; 250(6):878-87. https://doi.org/10.1097/SLA.0b013e3181b21c7b.

11. Yin C, Li D, Sun Z, Zhang T, Xu Y, Wang Z, et al. Clinicopathologic features and prognosis analysis of mucinous gastric carcinoma. Med Oncol. 2012; 29(2):864-70. https://doi.org/10.1007/s12032-011-9825-z.

12. Yasuda K, Adachi Y, Shiraishi N, Yamaguchi K, Shiromizu A, Kitano S. Pathology and prognosis of mucinous gastric carcinoma. J Surg Oncol. 2001;76:272-7.

13. Isobe T, Hashimoto K, Kizaki J, Matono S, Murakami N. KinugasaT et al. Characteristics and prognosis ofmucinous gastric carcinoma. Mol Clin Oncol. 2015;3(1):44-50

14. Adachi Y, Yasuda K, Inomata M, Shiraishi N, Kitano S. SugimachiK. Clinicopathologic study of early-stage mucinous gastric carcinoma. Cancer. 2001;91(4):698-703. https://doi.org/10.1002/1097-0142(20010215)91:4<698::A ID-CNCR1054>3.0.CO;2-O.

15. Lin CL, Zhu GW, Huang YJ, Zheng W, Yang SG, Ye JX. Operable gastric adenocarcinoma with different histological subtypes: Cancer specifc survival in the United States. Saudi J Gastroenterol. 2020;26(1):46-52. https://doi. org/10.4103/sjg.SJG_406_19.

16. Zhang M, Zhu GY, Zhang HF, Gao HY, Han XF, Xue YW. Clinicopathologic characteristics and prognosis of mucinous gastric carcinoma. J Surg Oncol. 2010:102(1):64-7. https://doi.org/10.1002/jso.21533.

17. ISOBE T, HASHIMOTO K, KIZAKI J, MATONO S, MURAKAMI N, KINUGASA T, et al. Characteristics and prognosis of mucinous gastric carcinoma. MOLECULAR AND CLINICAL ONCOLOGY. 2015;3(1):44-50. https://doi.org/1 $0.3892 /$ mco.2014.447.

18. Yuan Y, Chen Z, Chen J, Huang W, Peng J, Ye J, et al. Mucinous gastric carcinoma: an update of clinicopathologic features and prognostic value from a retrospective study of clinical series. Int J Clin Exp Pathol. 2018;11(2): $813-21$

19. Kim DY, Park YK, Joo JK, Ryu SY, Kim YJ, Kim SK, et al. Clinicopathological characteristics of signet ringcell carcinoma of the stomach. ANZ J Surg. 2004:74:1060-4

20. Gronnier C, Messager M, Robb WB, Thiebot T, Louis D, Luc G, et al. Is the negative prognostic impact of signet ring cell histology maintained in early gastric adenocarcinoma. Surgery. 2013;154(5):1093-9. https://doi.org/10.101 6/j.surg.2013.05.020

21. Jiang CG, Wang ZN, Sun Z, Liu FN, Yu M, Xu HM. Clinicopathologic characteristics and prognosis of signet ring cell carcinoma of the stomach: results from a Chinese monoinstitutional study. J Surg Oncol. 2011;103(7): 700-3. https://doi.org/10.1002/jso.21878.

22. Chiu CT, Kuo CJ, Yeh TS, Hsu JT, Liu KH, Yeh CN, et al. Early signet ring cell gastric cancer. Dig Dis Sci. 2011;56(6):1749-56. https://doi.org/10.1007/s1062 0-010-1487-8.

23. Liu Z, Wu S, Gou S, Li Y, Wu H, Li Y. A Population-Based Study of the Incidence and Survival of Anorectal Gastrointestinal Stromal Tumor. Med Sci Monit. 2019;21(25):5408-17.

24. Wei J, Yang P, Huang Q, Chen Z, Zhang T, He F, et al. Proximal versus total gastrectomy for proximal gastric cancer: a surveillance, epidemiology, and end results program database analysis. Future Oncol. 2021;17(10):1185-95. https://doi.org/10.2217/fon-2020-1071

25. Japanese Gastric Cancer Association. Japanese classification of gastriccarcinoma: 3rd English edition. Gastric Cancer. 2011;14(2):101-12. https://doi.org/10.1007/s10120-011-0041-5.

26. Liu K, Wan J, Bei Y, Chen X, Lu M. Prognostic impact of different histological types on gastric adenocarcinoma: a surveillance, epidemiology, and end results database analysis Pathol. Oncol Res. 2017:23(4):881-7. https://doi. org/10.1007/s12253-017-0198-2

27. Zheng D, Cooke D. A survival comparison of mucin-producing adenocarcinoma of the esophagus to conventional adenocarcinoma after Esophagectomy. Am Surg. 2013;79(1):49-53. https://doi.org/10.1177/ 000313481307900128

\section{Publisher's Note}

Springer Nature remains neutral with regard to jurisdictional claims in published maps and institutional affiliations. 